\title{
Resíduos sólidos e crime de poluição: avanços e retrocessos na legislação e na jurisprudência italianas
}

\author{
VICENZO MILITELLO \\ Doutor em Direito pela Università di Palermo (Itália). Diretor da Scuola \\ Specializzazione Professioni Legali da Università di Palermo (Itália). \\ VLADIMIR PASSOS DE FREITAS \\ Pós-Doutor (FDP/USP). Doutor e Mestre em Direito (UFPR). Professor do \\ Programa de Pós-Graduação Stricto Sensu (PUCPR).
}

\section{FERNANDA D. L.DAMACENA}

Doutora e Mestre em Direito (UNISINOS). Professora do Programa de Pós-Graduação Stricto Sensu (UCS).

\section{MARTA PALMISANO}

Doutora em Direito pela Università di Palermo (Itália). Professora da Università di Palermo (Itália).

Artigo recebido em 29/3/2020 e aprovado em 6/7/2020

SUMÁRIO: 1 Introdução - 2 A emergência do Direito Ambiental no sistema jurídico italiano 30 fenômeno da Ecomáfia e as ferramentas de combate. 4 Jurisprudência aplicada à matéria 5 Semântica normativa da poluição por resíduos sólidos no Brasil: algumas reflexões • 6 Conclusão 7 Referências.

RESUMO: O presente artigo apresenta a evolução normativa e jurisprudencial envolvendo crimes de poluição por resíduos sólidos na Itália, país que possui tradição no trato de condutas ilícitas ligadas à denominada Ecomáfia. A pesquisa foi orientada pelo método funcionalista e as técnicas de pesquisa utilizadas foram bibliográfica e jurisprudencial. Embora a evolução da legislação penal ambiental na Itália tenha focado mais a questão dos resíduos do que o Brasil, observam-se dificuldades em comum, como a deficiência na apuração dos crimes, a demora nos julgamentos com a consequente possibilidade de reconhecimento da prescrição e as falhas da legislação que permitem aos infratores evitar as condenações e o cumprimento de penas.

PALAVRAS-CHAVE: Resíduos Sólidos • Crimes Ambientais no Brasil e na Itália • Ecomáfia. 


\section{Solid waste and pollution crime: advances and setbacks in Italian legislation and jurisprudence}

CONTENTS: 1 Introduction. 2 The emergence of environmental law in the Italian legal system . 3 The Ecomafia phenomenon and the combat tools . 4 Jurisprudence applied to the matter. 5 Normative semantics of solid waste pollution in Brazil: some reflections . 6 Conclusion .7 References.

ABSTRACT: This article presents the normative and jurisprudential evolution involving crimes of pollution by solid waste in Italy, a system that has a tradition in dealing with illicit behaviors linked, for example, to Ecomafia. The research followed the functionalist method and bibliographic and jurisprudential research techniques. Although the evolution of environmental penal legislation in Italy has focused more on the issue of waste than in Brazil, there are difficulties in common, such as the deficiency in the investigation of crimes, the delay in the trials, with the consequent possibility of recognizing the limitation period and flaws of the legislation that allow offenders to avoid convictions and serving time.

KEYWORDS: Solid Waste - Environmental Crimes in Brazil and Italy . Ecomafia.

\section{Delitos de residuos sólidos y contaminación: avances y retrocesos en la legislación y en la jurisprudencia italianas}

CONTENIDO: 1 Introducción . 2 La emergencia del Derecho Ambiental en el ordenamiento jurídico italiano. 3 El fenómeno de la Ecomafia y las herramientas de combate . 4 Jurisprudencia aplicada a la materia. 5 Semántica normativa de la contaminación por residuos sólidos en Brasil: algunas reflexiones 6 Conclusión. 7 Referencias.

RESUMEN: Este artículo presenta la evolución normativa y jurisprudencial de los delitos de contaminación por residuos sólidos en Italia, país que tiene tradición en el tratamiento de conductas ilegales relacionadas con la denominada Ecomafia. La investigación se guió por el método funcionalista y las técnicas de investigación utilizadas fueron bibliográficas y jurisprudenciales. Si bien la evolución de la legislación penal ambiental en Italia se ha centrado más en el tema de los residuos que en Brasil, existen dificultades comunes, como la deficiencia en la investigación de los delitos, la demora en los juicios con la consiguiente posibilidad de reconocer la prescripción y la fallas en la legislación que permiten a los infractores evitar condenas y cumplir condenas.

PALABRAS CLAVE: Residuos sólidos . Crímenes ambientales en Brasil e Italia • Ecomafia. 


\section{Introdução}

AS taxas de resíduos sólidos têm aumentado mundialmente e assumido papel acordo com relatório do Banco Mundial (BANCO MUNDIAL, 2019), em 2016, as cidades geraram 2,01 bilhões de toneladas desses resíduos, totalizando 0,74 kg por pessoa, por dia. Com o rápido crescimento populacional e urbanização, estima-se que a geração anual deva aumentar para 3,40 bilhões de toneladas até 2050.

0 fracasso das entidades, instituições e estruturas jurídicas na mitigação e enfrentamento desse cenário representa uma perda coletiva e tem a capacidade de minar a convivência digna no planeta, a partir do comprometimento de inúmeros direitos fundamentais, dentre os quais: saúde e ambiente ecologicamente equilibrado

Ciente dessa realidade e a partir do direito comparado e da intersecção entre as esferas penal e ambiental, o presente artigo apresenta a análise da evolução normativa e jurisprudencial do enfrentamento dos crimes de poluição por resíduos sólidos na Itália, sistema jurídico que possui tradição no trato dessas condutas ilícitas, que abrangem, inclusive, a ação de facções criminosas na área, a chamada Ecomáfia.

Por outro lado, este artigo demonstra, também, como a matéria é tratada no Brasil, as diferenças da ação criminosa nos dois países e as dificuldades para punir-se criminalmente os infratores.

A pesquisa foi orientada pelo método funcionalista, o qual pode ser definido como aquele que pretende identificar respostas jurídicas similares ou distintas em conflitos sociais semelhantes, mesmo que ocorram em lugares distintos no mundo.

As técnicas de pesquisa eleitas foram a bibliográfica e a jurisprudencial.

\section{A emergência do Direito Ambiental no sistema jurídico italiano}

A Itália, como muitos países da Europa e de outros continentes, teve que lidar com os resultados do progresso econômico e as consequências de suas atividades na vida dos indivíduos e da coletividade. A dificuldade de encontrar o equilíbrio entre as diversas necessidades influenciou as respostas regulatórias que o sistema jurídico italiano preparou sobre o assunto. Isso ocorreu a partir do quadro das indicações supranacionais e, em especial, das da União Europeia. Entre elas, assumiu significado particular a definição de um sistema penal para confrontar as ofensas mais graves ao meio ambiente, tendo em vista a importância que o assunto assumiu gradualmente na representação coletiva dos valores envolvidos (AMARELLI, 2015, p. 1). 
Somente no curso do século $X X$, começou-se a dar maior atenção às diferentes categorias de bens ambientais, essencialmente graças à difusão gradual da consciência das repercussões que os danos e a poluição ambientais podem ter na vida de cada indivíduo. Em um segundo momento, desenvolveram-se algumas formas de interferência no crime organizado, com destaque para organizações do tipo mafiosa, na exploração de atividades com forte impacto ambiental. Essa postura decorreu da necessidade de enfrentamento das relações entre organizações criminosas e economia.

Até recentemente não era possível encontrar, no sistema jurídico italiano, uma definição normativa de ambiente como um bem jurídico a ser protegido legalmente. A referência ao meio ambiente entra na Carta Constitucional Italiana pelos artigos 9, § 2ำ (proteção da paisagem), e 32 (proteção da saúde). Em 2001, com a reforma do Título $V$ da Constituição, a noção de meio ambiente aparece no artigo 117, e estabelece competência exclusiva do Estado, sobre a matéria da "proteção do meio ambiente, ecossistema e patrimônio cultural", e concorrente, na "melhoria do patrimônio cultural e ambiental". A ausência de uma formulação de princípios é acompanhada pela falta de referências aos princípios de desenvolvimento sustentável e aos direitos das gerações futuras encontradas em outras constituições, como a alemã (GG, art. 20a). Além disso, a noção de ambiente tem sido interpretada de maneira diversa, sendo por um lado antropocêntrica (na qual sua proteção é funcional para as necessidades de desenvolvimento humano) e, por outro, ecocêntrica (em que ele é protegido como tal), em sentido amplo ou restrito, de acordo com teorias pluralistas ou monísticas (CATENACCI, 1996; SIRACUSA, 2007; DE SANTIS, 2002). As consequentes dificuldades de identificar com precisão o bem jurídico tutelado penalmente, refletem-se na problemática de técnicas e de conteúdos criminalizantes desenvolvidos que não venham a sacrificar os princípios de legalidade, taxatividade e ofensa de relevância constitucional (BERNASCONI, 2008, p. 9; RAMACCI, 2003, p. 34 e ss.).

O deficit do sistema de proteção ambiental é evidente também no nível extrapenal. De fato, não existe um conjunto homogêneo de regras. Com particular referência à regulamentação de resíduos, o assunto está confinado principalmente à legislação existente fora dos Códigos, com pouca eficácia preventiva e dissuasiva. Por outro lado, até recentemente, o Código Penal previa alguns casos, principalmente de perigo abstrato, sem um aparato de sanção adequado e era absolutamente impróprio para o enfrentamento dos eventos mais graves de poluição e desastre ambiental. 


\subsection{Fontes reguladoras italianas sobre Direito Ambiental e gestão de resíduos. 0 Texto Único Ambiental: Decreto Legislativo no 152/2006}

No contexto de fontes internas, o quadro regulatório é complexo, articulado e multifacetado, resultado de uma estratificação legislativa substancial.

Uma primeira referência normativa é encontrada no nível constitucional, nos

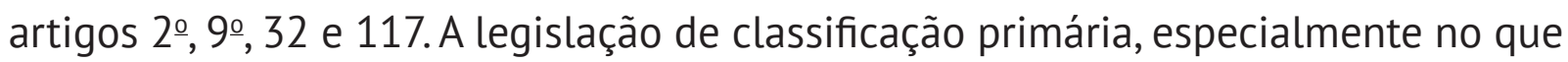
diz respeito à questão dos resíduos, é vastíssima e composta, dentre outros: pelo Decreto Legislativo no 133, de 11 de maio de 2005 - sobre crimes relacionados à incineração de resíduos; pela Lei no 128, de 2019 - que rege a qualificação dos resíduos; e pela Lei oㅡ 117, de 2019 - que transpõe as diretivas relativas aos resíduos. No entanto, a disciplina fundamental nesta matéria está contida no Decreto Legislativo oo 152, de 2 de abril de 2006, conhecido como Texto Único em matéria Ambiental (doravante citado pela sigla TUA), que prevê Regulamentos Ambientais, que reformaram toda a legislação ambiental interna (RIVA, 2006).

Em particular, o texto dedica a parte IV à regulamentação de resíduos (artigos 117-266). No entanto, as regulamentações nacionais e europeias, muitas vezes não coordenadas entre si, não especificam o que significa descarte ou transporte de resíduos, nem classificam claramente os resíduos perigosos e não perigosos, criando problemas na aplicação da legislação. Nos artigos 179-182, ações de prevenção e redução da produção de resíduos e recuperação são medidas prioritárias; o descarte é compreendido como uma solução residual. 0 artigo 183 do TUA fornece a seguinte definição de resíduo: "qualquer substância ou objeto que o detentor descarte ou tenha a intenção ou obrigação de descartar". No artigo 184, os resíduos são divididos, de acordo com sua origem, em resíduos municipais e especiais; de acordo com suas características de periculosidade, em resíduos perigosos e não perigosos; e, conforme seu destino final, em não reutilizáveis e reutilizáveis. A parte IV do texto legislativo também contempla alguns casos de natureza contravencional, que traçam os perfis da conduta do ciclo de gerenciamento de resíduos (RIVA, 2006).

São exemplos dessas tipificações: o abandono de resíduos, nos termos do artigo 255; a atividade não autorizada de gerenciamento de resíduos, nos termos do artigo 256; a criação ou gerenciamento dos chamados aterros ilegais e o aterro realizado e gerenciado na ausência das autorizações prescritas por lei, nos termos do artigo 256, § 3; ; a combustão ilícita de resíduos, nos termos do artigo 256 bis; o regulamento sobre a recuperação de locais, nos termos do artigo 257; a violação das obrigações de comunicação, manutenção dos registros e formulários obrigatórios, 
nos termos do artigo 258 (com exceção do parágrafo 4º); o tráfico ilícito de resíduos, nos termos do artigo 259, e as violações inerentes ao sistema de informática (TI) para monitorar a rastreabilidade de resíduos (260 bis). 0 artigo 260, que previa o crime de atividades organizadas para o tráfico ilícito de resíduos, foi transposto para o art. 452 do Código Penal Italiano.

Os regulamentos setoriais devem ser lidos à luz de quatro princípios fundamentais implementados pelo TUA: poluidor-pagador, prevenção, precaução e desenvolvimento sustentável. No entanto, deve-se notar que, apesar da seriedade das ofensas e das repercussões negativas que resultam na saúde e no meio ambiente, o sistema de sanções previsto é inadequado. Basta pensar no tráfico ilícito de resíduos, punido com multa de 1.550 a 26.000 euros e prisão por até dois anos.

A estratificação legislativa, que tem sido progressivamente testemunhada em questões ambientais, fornece uma imagem não homogênea e inorgânica das fontes reguladoras, especialmente em matéria de resíduos. Além disso, os casos contidos no TUA costumam ser caracterizados pelo surgimento do caráter acessório do Direito Penal em relação às disposições administrativas, de modo que a conduta típica acaba sendo complementada pela não observância de requisitos administrativos, independentemente da verificação de um evento de dano ou perigo concreto (SIRACUSA, 2007, p. 165 e ss.; CATENACCI, 2012).

\subsection{A implementação da Diretiva 2008/99/CE na Itália: o Decreto Legislativo 121/2011 e a responsabilidade dos órgãos ambientais}

O Direito Internacional e o Direito Europeu desempenharam um papel decisivo na evolução da proteção ambiental, considerando a natureza transfronteiriça do bem jurídico tutelado e o vínculo estreito de interdependência entre a proteção de direitos humanos, desenvolvimento sustentável e proteção ambiental (ROMANO, 2003).

A esse respeito, observe-se a Diretiva 2008/98/CE, relativa aos resíduos, modificada pelas diretivas 2018/851/UE e 2008/99/CE, que dispõem sobre a proteção penal ambiental. Referida diretiva introduziu, no artigo 5, a obrigação de os Estados-Membros sujeitarem a sanções penais adequadas, proporcionadas, efetivas e dissuasivas algumas violações graves à proteção do ambiente e à gestão de

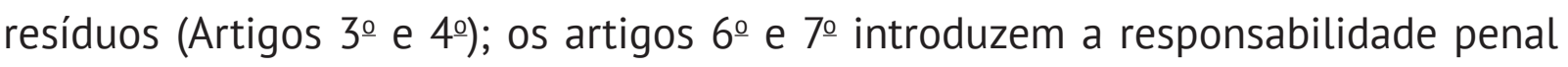
das pessoas jurídicas e a adoção, pelas mesmas, de sanções eficazes, proporcionais e dissuasivas. A diretiva 2008/99/CE gerou uma virada histórica no panorama do Direito Penal Ambiental italiano, constituindo também o primeiro caso em que 
um ato europeu impôs, explicitamente, obrigações de incriminação aos EstadosMembros, a fim de garantir, por meio do uso de sanções penais, proteção mais efetiva do patrimônio jurídico ambiental e gerenciamento correto do ciclo de resíduos. A Diretiva 2008/99/CE foi incorporada ao ordenamento jurídico italiano pelo Decreto Legislativo Italiano 121, de 7 de julho de 2011 (DE SANTIS, 2008, p. 668 e ss.).

No entanto, essa intervenção não foi responsável por uma mudança radical de paradigma do sistema penal ambiental. Afinal, a estrutura dos casos incriminadores existentes permaneceu basicamente inalterada, limitando-se às hipóteses tipificadas pelos regulamentos europeus ao contexto de criminalizar situações de perigo, sujeitas a uma antecipação do limiar punível e focadas, principalmente, em exceder valores-limite, na falha da conformidade com os procedimentos administrativos e falta de cooperação com as autoridades de supervisão. As medidas sancionatórias também continuam modestas e, portanto, não particularmente dissuasivas (AMARELLI, 2016, p. 405 e ss.).

O Decreto Legislativo no 121/2011 introduziu o artigo 25 décimo primeiro, previsto anteriormente no Decreto Legislativo no 231/2001, que estendeu a responsabilidade das pessoas coletivas a certos crimes ambientais, incluindo os referidos nos artigos 256, 257, 258 § 4으, 259, 260 do TUA em relação aos resíduos. Essa foi uma posição fundamental adotada pelo legislador, especialmente porque muitas vezes o sujeito realmente responsável por eventos prejudiciais ao meio ambiente é o próprio corpo empresarial, como um centro de interesse autônomo, persistente ao longo do tempo e punível também com relação a crimes de poluição com efeitos diferidos.

Entretanto, mesmo diante desse cenário, a estrutura regulatória pouco consistente persistiu, especialmente à luz da falta de coordenação das disposições recém-introduzidas com o aparato regulador existente.

\subsection{A reforma dos crimes ambientais: Lei $n^{-0} 68$, de 22 de maio de 2015}

As insuficiências do sistema regulatório e a incapacidade de encontrar uma resposta imediata para fenômenos de grande clamor social, como a Ecomáfia ou os grandes danos ao meio ambiente, permaneceram por muito tempo no sistema jurídico italiano, devido a um flagrante vácuo legislativo. A ineficácia do sistema regulatório se manifestou, em todo o seu alcance, nas ocasiões de eventos mais macroscópicos de desastres ambientais.A essa ineficácia, a jurisprudência historicamente subsumiu, no silêncio da lei, no fato típico do chamado desastre inominado, referido no artigo 
434 do Código Penal Italiano. Destaque particular merece a segunda parte do artigo 434, que incrimina, junto com o desabamento dos edifícios, outros desastres dolosos, ampliando a área de tipicidade da provisão e antecipando o limite punível.

A inadequação dessa solução e a resultante interpretação lançaram luz sobre a necessidade de prever um caso ad hoc capaz de lidar com macro eventos de danos ao meio ambiente. Nesse contexto, a Lei ํㅜ 68, contendo "Disposições relativas a crimes contra o meio ambiente" (ITÁLIA, 2015), marca uma quebra radical da abordagem subjacente ao Decreto Legislativo no 152/2006. A novidade mais importante nesse passo foi a inserção, no Código Penal, do novo título VI bis, dedicado a novos crimes contra o meio ambiente, estruturado na forma de crimes de perigo e danos concretos. Entre os novos delitos, introduziram-se os crimes de atividades organizadas para 0 tráfico ilícito de resíduos e de omissão na recuperação, nos termos dos artigos 452 e seguintes, do Código Penal Italiano.

Além do artigo 452 décimo quarto, o Decreto Legislativo oㅡ 21, de 2018 também introduziu crimes de poluição ambiental (art. 452 bis do código penal); morte ou lesão como consequência do crime de poluição ambiental (art. 452 terceiro); desastre ambiental (art. 452 quarto), crimes culposos contra o meio ambiente (art. 452 quinto); crime de tráfico e abandono de material altamente radioativo (art. 452 sexto); e crime de impedir o controle (art. 452 sétimo), a agravante ecomafiosa (art. 452 oitavo), a "circunstância agravante ambiental" (art. 452 nono), o instituto do arrependimento ativo (art. 452 décimo), a obrigação de restaurar o estado dos locais (art. 452 décimo segundo) e confisco (art. 452 décimo primeiro).

A reforma também permitiu o aumento de algumas penalidades por decreto e a duplicação dos prazos de prescrição para os delitos contidos no novo Título VI bis. No entanto, o mesmo regime não foi estendido a outras ofensas ambientais contidas no Código Penal (por exemplo, art. 434), o que vale para os casos de crimes envolvendo os resíduos, com a consequência de que ofensas mais graves podem estar sujeitas a prazos prescricionais menores. Pense-se no crime de combustão ilegal de resíduos, nos termos do artigo 256 bis do TUA, que, apesar das sérias consequências que pode ter sobre a saúde e o meio ambiente, permanece sujeito ao prazo de prescrição comum (COTTU, 2018, p. 273 e ss.). Da mesma forma, a reforma da prescrição não se aplica à responsabilidade das pessoas jurídicas em questões ambientais.

Após a reforma, três tipos de intervenção podem ser observados no projeto geral de combate a danos ambientais (BERNASCONI, 2016; RAMACCI, 2015, p. 68; RIVA, 2015) em matéria de resíduos: por um lado, uma abordagem extra-codicista, 
na qual o perigo de violações prevalece onde o ambiente é protegido apenas indiretamente; por outro lado, uma abordagem codicista, focada em casos de danos e perigos concretos; finalmente, um sistema de emergência, delimitado em razão do âmbito territorial ou do objeto de tutela (CONSULICH, 2018, p. 9 e ss.).

Em relação à responsabilidade de pessoas jurídicas, a Lei no68/2015 ampliou o catálogo de infrações previstas no artigo 25 do Decreto Legislativo no 231/2001.

Apesar das repercussões certamente positivas produzidas pela reforma, surgem algumas inconsistências que levantam dúvidas sobre sua real eficácia para fins de proteção criminal efetiva do meio ambiente. Basta refletir sobre a falta de coordenação com outras fontes reguladoras, incluindo o Decreto Legislativo no 152/2006, e a redação de muitos tipos criminais que permanecem de difícil aplicação processual, podendo gerar, ainda, conflitos com o princípio da legalidade.

Podem ser destacados, ainda, alguns problemas relacionados à responsabilidade corporativa. A insuficiência da nova disciplina pode ser observada tanto quanto à coordenação entre a parte geral e a especial do Decreto Legislativo no 231/2001, bem como em relação ao catálogo de infrações, que continua a apresentar lacunas incompreensíveis (como a não inclusão do crime de falha na limpeza de locais poluídos, nos termos do artigo 452 do Código Penal Italiano), e ao nível de inconsistências no regime sancionatório.

Ademais, o TUA introduziu a possibilidade de extinguir as sanções ambientais previstas para os crimes de abandono de resíduos, gestão de resíduos não autorizados, dumping ilegal, falha na limpeza, tráfico ilícito de resíduos, através do cumprimento de meras disposições administrativas e multas (artigo 318, TUA). Finalmente, algumas regulamentações do TUA foram necessárias para que as regras fossem efetivamente aplicáveis, bem como uma redução ad unum da legislação especial, que continua a ser estranha ao conteúdo do TUA.

A Corte de Cassação da Itália, no acórdão 46170, de 21 de setembro de 2016, tratou pela primeira vez do crime de poluição ambiental (artigo 452 bis do Código Penal Italiano), que se caracteriza por ser vago e impreciso, especificando os elementos constitutivos e, em particular, o conteúdo da cláusula de abuso e o significado dos conceitos de prejuízo e deterioração significativos e mensuráveis. No que se refere à dimensão judicial de aplicação da legislação, apesar dos esforços realizados até o momento deve-se notar que aproximadamente $26 \%$ dos procedimentos de infrações da Corte de Cassação pertencem à esfera ambiental. Dos 19 casos identificados, 6 dizem respeito à matéria dos resíduos. Os dados 
anuais sobre crimes ambientais - "Ecomáfia 2017" -, fornecidos pela associação Legambiente, relatam 25.899 crimes ambientais, mais de 70 por dia. Cerca de 6.000 dizem respeito à gestão de resíduos, com tendência ao crescimento.

\section{0 fenômeno da chamada Ecomáfia e as ferramentas de combate}

Dentre os setores que mais atraem a atenção do crime organizado, as atividades que afetam o meio ambiente são de importância central. Nesse sentido, o termo ecomáfia (LO MONTE, 2003, p. 254 e ss.; BONGIORNO, 2012, p. 126; PLANTAMURA, 2007, p. 73) tornou-se difundido pela associação ambiental Legambiente, com o objetivo de referir-se a associações criminosas dedicadas ao tráfico e ao descarte ilícito de resíduos. O termo evoca dois conceitos diferentes, mas relacionados: "a dimensão sistêmica do crime ambiental" e "a economia suja devido às infiltrações inerentes ao método da máfia” (ROMANO, 2013, p. 237). De fato, o setor ambiental, vinculado a um grande volume de interesses econômicos, muitas vezes presta-se ao interesse de organizações criminosas, que operam por meio de vínculos recíprocos, também em escala transnacional, bem como com instituições e entidades que operam na economia legal. Em complemento, esta realidade acaba sendo potencializada pela legislação inadequada.

A expansão do fenômeno nem sempre é combatida com medidas de prevenção e repressão adequadas para enfrentá-la. No sistema jurídico italiano, os artigos 416 bis e 452 do Código Penal representam dois instrumentos de defesa social. 0 primeiro pune associações do tipo máfia e o segundo regula as "atividades organizadas para o tráfico ilegal de resíduos". O tipo que representa o primeiro crime ambiental introduzido no sistema também foi incluído no artigo 51, parágrafo 3 bis, do Código Penal Italiano, entre os assuntos da competência da Direção Distrital Antimáfia.

A ideia foi traçar, normativamente, a estreita conexão com os crimes típicos da máfia organizada. A conduta é complementada por operações múltiplas (já sancionadas como contravenções) referentes a grandes quantidades de resíduos, realizadas abusivamente, no contexto de atividades continuamente organizadas, com o objetivo de obter um lucro injusto. Todavia, esses elementos do tipo se caracterizam pela generalidade e efemeridade, o que torna difícil a aplicação. A provisão regulatória sobre o assunto, portanto, nem sempre é adequada e eficaz. Para combater o fenômeno em sua natureza sistêmica, reflete-se sobre a ausência do crime de associação para delinquir contra o meio ambiente; a esse respeito, todavia, 
podem vir em destaque a agravante ecomafiosa referida no art. 452 oitavo do Código Penal e a agravante ambiental, prevista no artigo 452 nono do mesmo Código.

\section{Jurisprudência aplicada à matéria}

Para entender o impacto que a questão da proteção criminal ambiental teve sobre a realidade italiana, é necessário verificar sua aplicação, a fim de testar sua capacidade efetiva para combater as formas de ofensa ao bem ambiental. $O$ exame deste artigo se limitará a três eventos de particular importância no debate público italiano, selecionados pela repercussão e seu impacto social, e por serem exemplos da dificuldade de uma tutela ambiental capaz de equilibrar a proteção do meio ambiente e o desenvolvimento econômico.

\subsection{Caso Eternit}

Este caso representa o julgamento criminal mais importante celebrado na Itália por mortes e doenças relacionadas à exposição ao amianto. 0 Tribunal de Turim considerou Stephan Schmidheiny, administrador da Eternit S.A., entre 1974 e 1986, responsável pelo desastre ambiental do qual decorreram doenças profissionais e mortes de milhares de pessoas ao longo do tempo, devido à exposição ao pó de amianto no local de trabalho e nas áreas circundantes, atribuindo-lhe, entre outros, o delito de desastre inominado, referido no artigo 434 do Código Penal Italiano (DE SANTIS, 2012, p. 166 e ss.; VERGINE, 2013, p. 535). A Corte de Apelação de Turim, em junho de 2013, confirmou a sentença de primeira instância, condenando o acusado a dezoito anos de prisão. No entanto, em 18 de novembro de 2014, a Corte de Cassação declarou que a prescrição do crime havia ocorrido antes mesmo da sentença de primeira instância.

A absolvição evidenciou a dificuldade, na ausência de lei específica regulando a prescrição em tais casos, de chegar-se a uma sentença de condenação na maior parte dos crimes de desastres ambientais, não tanto em razão do início dos prazos de prescrição, mas sobretudo em relação ao momento consumativo do crime e ao dies a quo do prazo prescricional (SIRACUSA, 2005, p. 198). Alguns dias após a sentença no caso Eternit, entrou em vigor a Lei no 68/2015, talvez para pôr um fim às controvérsias levantadas por alguns casos de desastres ambientais que ficaram impunes, devido à ausência de um regulamento que discipline expressamente o desastre ambiental. 
Segundo a Corte de Cassação, o momento de consumação do crime de perigo concreto prescinde da morte e das lesões após longos períodos de latência, devido à exposição prolongada ao pó de amianto; a morte e o ferimento, no entanto, não têm o status de elemento constitutivo do tipo, mas representam circunstâncias agravantes. Portanto, segundo uma interpretação constitucionalmente orientada, a consumação não pode ser deslocada além do exaurimento do iter criminoso típico e além do momento em que terminaram as emissões de poeira e resíduos do processamento de amianto, produzidas pelos estabelecimentos. Não além, todavia, de junho de 1986, foi declarada a falência das empresas do grupo. Em outras palavras, o tempus commissi delicti não identificado coincide com a cessação da conduta perigosa e, portanto, o mais tardar no fechamento da fábrica, sem ter que esperar pela produção dos efeitos.

A interpretação da Corte de Cassação, que acabou antecipando o momento de consumação do crime, destinando à prescrição todos os crimes baseados nessa estrutura, frustrou as tentativas dos juízes de primeiro grau e do Tribunal de Apelação de Turim que, a fim de evitar o risco da prescrição, tentaram identificar um momento diferente de consumação no artigo 434 (GATTA, 2014, p. 1-8) do Código Penal Italiano.

O caso Eternit ainda não terminou, pois se desdobrou no processo Eternit bis, dividido em quatro outras demandas: Turim, Vercelli, Reggio Emilia e Nápoles. 0 Tribunal de Turim condenou o empresário suíço Schmidheiny a quatro anos de prisão, por acusações de homicídio culposo pela morte de dois trabalhadores. No julgamento realizado em Vercelli, houve denúncia por homicídio doloso que resultou na morte de cerca de 400 pessoas. Em Reggio Emilia, o processo também está em andamento. 0 Foro Criminal de Nápoles, em 25 de janeiro de 2019, acatou a acusação de homicídio com dolo eventual em relação à morte de oito pessoas. Em 31 de maio, o pedido de absolvição por violação do ne bis in idem foi rejeitado no mesmo Juízo Criminal de primeira instância, porque, ao contrário do anterior, o crime de homicídio foi contestado no novo julgamento.

Nesse ponto, é interessante observar como mudou a estratégia processual da acusação. No primeiro julgamento, a Eternit não contestou a responsabilidade pelos homicídios simples e lesões, mas rejeitou um único macro evento de desastre. Essa escolha certamente levou a uma simplificação do ônus da prova, pois a promotoria não precisou demonstrar, em relação aos eventos individuais, a relação causal com relação à exposição a fibras de amianto. 


\subsection{Ilva de Taranto}

Outro episódio importante, sintomático das lacunas legislativas presentes no sistema jurídico italiano, é representado pela conhecida história da Ilva de Taranto. Ainda em andamento, o evento iniciou um choque institucional entre política e judiciário, na tentativa de definir o delicado equilíbrio entre as necessidades ambientais, saúde e segurança pública, por um lado, e o interesse em manter a produção industrial, por outro (PULITANÒ, 2013, p. 44 e ss.).

A história está ligada à presença, no território de Taranto, da siderúrgica de Ilva, e remonta ao final dos anos 90, quando o Conselho de Ministros declarou Ilva uma área de alto risco ambiental. A grave situação de poluição levou à abertura de investigação, devido ao aumento considerável do número de indivíduos afetados e falecidos, à presença de dioxinas e poluentes depositados em lugares públicos e à morte de milhares de cabeças de gado, atribuíveis às emissões nocivas de usina siderúrgica Ilva.

O Tribunal de Taranto, em 23 de maio de 2014, reconheceu a responsabilidade criminal de todos os acusados pelos crimes de homicídio culposo múltiplo agravado (artigo 589 do Código Penal) e omissão dolosa, pela falta de precaução e prevenção de acidentes, agravadas pela verificação do desastre (art. 437 c.p.).

O Tribunal de Apelação de Lecce (sent. 563, de 2017), em reforma parcial, declarou a extinção da punibilidade, nos termos do artigo 437 do Código Penal, por prescrição, e confirmou a condenação por homicídio culposo somente para três ex-gerentes de fábrica.

Neste meio tempo, em 2012, foi adotada uma medida preventiva de sequestro de algumas áreas da empresa, tendo em vista a existência, na região Tarantina, de uma grave situação de emergência ambiental e sanitária, atribuível às emissões poluentes do estabelecimento Ilva S.A. O embargo foi seguido por uma autorização integrada ambiental (AIA), que impôs o adimplemento de determinadas condições até 2015 , anos depois postergado para 2023. 0 complexo industrial em questão foi declarado planta de interesse estratégico e foram concedidos mais três anos de produção, subtraindo-se a jurisdição criminal (art. 1ํㅡㄹ Decreto Legislativo no 207/2012, conv. L. 231/2012). Também foi aplicado o escudo criminal, ou seja, a não punição dos administradores pelos danos causados pela atividade industrial durante o período de implementação do plano de recuperação ambiental (art. 2º).

O Tribunal de Revisão confirmou o sequestro, tendo, todavia, exigido novas condições para a continuação das atividades. Em 26 de novembro de 2012, o juiz de instrução emitiu uma nova ordem de busca e apreensão preventiva de todos os 
produtos produzidos após a apreensão anterior, desde que fossem produto e lucro das atividades criminosas. Isso provocou a intervenção do governo, que aprovou novo Decreto Legislativo para garantir a continuidade da produção, em contraste com o provimento de sequestro e, portanto, privando de eficácia o provimento do juiz. Nesse momento se iniciava um conflito de atribuições perante o Tribunal Constitucional.

O Tribunal de Cassação (acórdão 2659, de 2014) também cancelou a apreensão, por não reconhecer cumpridas as condições estabelecidas nos artigos 19 e 53 do Decreto Legislativo o 231/2001. Por fim (acórdão 45935, de 12 de novembro de 2019), o mesmo Tribunal confirmou a absolvição da alta direção da Ilva, já ordenada pelo Tribunal de Apelação.

Em 2013, a Corte declarou a inadmissibilidade dos recursos. Paralelamente, as intervenções legislativas visavam alcançar um equilíbrio razoável entre interesses constitucionalmente relevantes. No mesmo ano, foi publicado novo Decreto Legislativo oㅜ $1 / 2015$, que autorizou a fábrica de Taranto a continuar a produção, mesmo em caso de apreensão criminal, e subtraiu da jurisdição criminal a conduta do Comissário Extraordinário de Ilva e dos sujeitos delegados. Esse decreto foi então alterado pelo Decreto Legislativo no 34, de 2019 (convertido na Lei no 58/2019), e pelo Decreto Legislativo oo 101, de 2019 (convertido na Lei no 128/2019), que excluiu a imunidade criminal.

A questão segue em aberto e atraiu o interesse da Corte Europeia de Direitos Humanos que, em 2019, acolheu recurso apresentado por alguns cidadãos residentes nas proximidades de Taranto, buscando a condenação da Itália por não proteger o direito à saúde dos cidadãos e o consequente reconhecimento da violação do direito à vida privada (artigo $8^{\circ} \mathrm{CEDH}$ e artigo $13 \mathrm{TEDH}$ ).

\subsection{A emergência de resíduos na Campânia: a Terra das Fogueiras}

A emergência dos resíduos em Campânia iniciou com o Decreto Legislativo de 11 de fevereiro de 1994, que proclamou o estado de emergência e nomeou um comissariado extraordinário para a gestão dos resíduos.

A área ficou conhecida como Terra das Fogueiras, expressão utilizada para indicar a vasta zona da Itália meridional, onde ocorriam o enterro de resíduos tóxicos e o desencadeamento de incêndios contínuos, inclusive dentro dos aterros ilegais, para liberar espaço e descartar novos resíduos. Os resíduos urbanos e especiais queimados representam a principal fonte de poluição na área, agora totalmente comprometida, e com a identificação de sérios danos à saúde, ao meio ambiente e à agricultura. 
Atualmente, a Campânia tem a maior taxa de mortalidade por câncer na Europa; além disso, cinco milhões de ecofardos não descartáveis ainda permanecem no território (correspondendo a 6 milhões de toneladas de resíduos). Mesmo diante desse contexto, as instituições públicas permitiram a continuação do regime, reiterando as declarações de estado de emergência e criando a oportunidade de adjudicação de contratos sob o regime de derrogação, violando os princípios de eficiência e bom desempenho da administração, referidos no artigo 97 da Constituição (FORZATI, 2015). Esse regime acabou se tornando uma rotina, durando cerca de 20 anos, atribuindo-se amplos poderes discricionários aos órgãos administrativos.

O fenômeno da Terra das Fogueiras também é resultado de conluios e relações corruptas, que contam com a participação de órgãos políticos,empresários, organizações criminosas e gerentes de serviços de resíduos - que compõem uma rede criminosa de negócios. A ecomáfia local sempre privilegiou o setor de gerenciamento e disposição de resíduos, ligado ao sistema de transporte, aterros, pedreiras e construções.

Esse contexto criou uma situação de impasse que dura anos em Campânia. 0 quadro caracteriza-se pela alternância de medidas propostas pelas autoridades judiciais por um lado, objetivando travar, emergencialmente, as práticas e o gerenciamento irracional dos procedimentos de descarte de resíduos, e do governo por outro lado, que propõe modelos regulatórios depreciativos que afetam medidas judiciais. A título de exemplo, em 2004, após 10 anos de regime comissarial, a justiça criminal interveio, atuando de forma suplente, e organizou o sequestro preventivo da instalação onde era produzido o Combustível Derivado do Tratamento de Resíduos (Cdr) de Campânia. Essa decisão foi seguida pelo Decreto Legislativo no 14/2005, que em face do sequestro feito, operando como uma blindagem, prevê a transformação das plantas de produção de Cdr em aterros indefinidamente, legitimando seu uso ilegal. Dessa forma, os locais de armazenamento tornaram-se aterros provisórios e legalizados, onde os fardos ecológicos foram depositados enquanto aguardavam a implementação do sistema regional de eliminação de resíduos. Esse regime temporário permanece até hoje.

Em 4 de novembro de 2013, o Tribunal de Nápoles se pronunciou sobre a questão, absolvendo todos os imputados e revogando o provimento de apreensão, declarando que o principal interesse dos imputados era evitar paralisia na coleta e tratamento de resíduos, enquanto o fracasso em atingir o alvo pode desencadear responsabilidades políticas, mas não criminais. A sentença foi fundamentada no artigo 60 do Decreto Legislativo oㅗ 90/2008, convertido na Lei ํo 210/2008 (seguida pelo Decreto 
Legislativo no 172/2008), que prevê um regime de emergência em uma emergência; de fato, "locais, áreas e plantas conectadas à gestão de resíduos" (ITÁLIA, 2008) são militarizados e formalmente transformados em áreas de interesse estratégico nacional, portanto protegidos por requisitos administrativos especiais e protegidos das verificações de legalidade e do cumprimento das normas de segurança.

Em 2014, o Tribunal de Cassação, por meio da sentença 45001, finalmente cancelou a apreensão de 70 hectares de terra, com remessa ao Tribunal de Nápoles, por evidências insuficientes.

Em 17 de janeiro de 2019, o Tribunal de Apelação de Nápoles reconheceu a prescrição de alguns crimes. Por essa razão, condenou apenas alguns dos acusados pelos crimes de desastre ambiental e tráfico ilícito de resíduos, com agravante de tratar-se de crime de máfia. Uma decisão paralela, em 2017, condenou por desastre ambiental dois dos principais responsáveis pelo aniquilamento do território da Campânia, hoje, todavia, encontram-se libertados da prisão pelo benefício do indulto.

Por fim, a Corte de Justiça da União Europeia também interveio na emergência de Campânia e, em 2010, condenou a Itália por violação da Diretiva 2006/12/CE. Em 10 de janeiro de 2012 (decisão Di Sarno), a mesma Corte condenou o país por não atender adequadamente à emergência de resíduos na Campânia, constatando a violação dos artigos 8 e 13 da Corte Europeia de Direitos Humanos.

Em março de 2019, o mesmo Tribunal de Direitos Humanos aceitou novas demandas contra o governo italiano por violação dos direitos fundamentais. As alegações são as de que, a partir do final dos anos 1980, devido à poluição na grande região da Campânia, por meio de derramamento, combustão, enterro de resíduos perigosos e gerenciamento de aterros ilegais, muitos habitantes tiveram a saúde seriamente afetada.

\section{Semântica normativa da poluição por resíduos sólidos no Brasil: algumas reflexões}

O artigo 225 da Constituição federal estabelece um direito-dever público e privado em relação ao ambiente, de maneira que "todos têm direito ao meio ambiente ecologicamente equilibrado" (BRASIL, 2020).

$\mathrm{Na}$ esfera legal, muito antes da vigência da Constituição de 1988, o artigo 3o, incisos III e IV, da Lei no 6.938, de 1981, trouxe parâmetros orientadores dos conceitos de poluição e de poluidor. Especificamente em relação à poluição por resíduos sólidos, a Lei no 12.305, de 2010, preencheu importante lacuna na legislação 
ambiental brasileira, ao definir resíduos sólidos e estabelecer uma série de institutos e instrumentos para o enfrentamento da questão.

A responsabilidade por danos causados ao meio ambiente no Brasil, decorrente da poluição por resíduos, encontra seu fundamento axiológico na Constituição Federal, que incide diretamente sobre as relações públicas e privadas, com a possibilidade de tríplice responsabilidade (administrativa, civil e criminal). Os crimes ambientais estão previstos na Lei no 9.605, de 1998, com destaque para os tipos previstos nos artigos 54 e 56.

Além das normas citadas, relevantes atos administrativos federais, estaduais e municipais as complementam. Entre eles, 15 Resoluções do Conselho Nacional do Meio Ambiente - CONAMA, que tratam dos mais variados temas (e.g., Resolução no 450/2012, sobre recolhimento, coleta e destinação final de óleo lubrificante usado ou contaminado) (CONAMA, 2012).

Em termos constitucionais, as atribuições e responsabilidades pela coleta e destino dos resíduos sólidos competem aos três entes da Federação. Essa competência ambiental se interconecta com a perspectiva da saúde pública, o que pode ser vislumbrado nos artigos 24, XII e 30, I, da Constituição federal. Vida saudável e ambiente ecologicamente equilibrado são dois pilares constitucionais que miram à existência digna. Exatamente por essa razão, condutas que exponham a riscos ou prejudiquem o ambiente e a vida receberam atenção do legislador constitucional, e foram regulamentadas por legislações infraconstitucionais penais posteriores, vez que o Direito Penal tutela os bens jurídicos mais relevantes para a vida em sociedade.

Todavia, ao contrário de como na Itália, estas modalidades de atividade criminosa não despertam maior interesse das organizações criminosas. $O$ espaço territorial do Brasil é muito maior do que o daquele país e, por isso, é mais fácil e menos custoso aos infratores atuarem em aterros ilegais, os chamados lixões. É verdade que em um momento precedente, ou seja, nas licitações, as disputas originam ações penais pela prática de corrupção e outros crimes conexos.

No entanto, ainda que existam delitos envolvendo fraudes na licitação (BRASIL, 2011) - via de regra as que envolvem o recolhimento de lixo urbano -, os precedentes judiciais são, na maioria, relacionados com a poluição do solo e de recursos hídricos. Nesse contexto, não raras vezes a municipalidade está presente no polo passivo das demandas, seja por ação ou omissão.

Embora já bastante evoluída e, em alguns aspectos, aparentemente mais completa do que a italiana, a legislação penal ambiental brasileira voltada à 
imputação das más condutas de poluição do solo carece de ajustes. Talvez um dos mais relevantes seja a clara definição de critérios de imputação, o que reduziria a abertura típica dos tipos penais ambientais que, por vezes, geram insegurança jurídica. Seria relevante que, passados mais de 10 anos da entrada em vigor da legislação dos resíduos, fosse realizada uma análise acerca da sua efetividade para o ambiente e a sociedade brasileira. $O$ levantamento de dados a esse respeito apontaria alguns indicadores e representaria uma ótima fonte de inspiração para novas proposições e alterações.

O art. 54 da Lei no 9.605, de 1998, é exemplo de tipo penal aberto, com cláusulas normativas, de cunho valorativo, que estão aquém das exigências do princípio da legalidade em sua vertente taxatividade-determinação da lei penal. No entanto, em nenhum momento se cogitou de declarar-se a sua inconstitucionalidade por ofensa ao princípio da legalidade, porque não há como ser de outra forma, visto que seria impossível ao legislador descrever todas as formas de poluição existentes, nem prever as que surgirão com o tempo. Assim, cabe ao Judiciário definir a existência do crime no caso concreto. Por exemplo, dando o significado de "poluição de qualquer natureza em níveis tais que".

Em 2010, com a edição da Lei no 12.305, o legislador teve uma segunda oportunidade de rever a tipificação do art. 54, tornando-o mais claro e até reformulando suas penas, já que, para casos graves, 1 ano de reclusão é pena por demais branda. Todavia, no art. 51 da lei de resíduos sólidos, estabeleceu-se que:

(...) sem prejuízo da obrigação de, independentemente da existência de culpa, reparar os danos causados, a ação ou omissão das pessoas físicas ou jurídicas que importe inobservância aos preceitos desta Lei ou de seu regulamento sujeita os infratores às sanções previstas em lei, em especial às fixadas na Lei no 9.605, de 1998. (BRASIL, 2010).

Observe-se que o tipo penal do crime de poluição (art. 54) na Lei nº 9.605, de 1998, não se refere especificamente aos resíduos sólidos. Praticamente não se aborda esta específica forma de poluição no Brasil, sendo a norma deficiente na relação entre lixo, saúde e meio ambiente. Em sendo assim, orientado pelo exemplo italiano, um projeto de lei que ampliasse a Lei no 9.605, de 1998, para torná-la mais específica em relação à matéria, poderia considerar a inclusão dos seguintes crimes: atividades organizadas para o tráfico ilícito de resíduos; omissão dolosa pela falta de prevenção de acidentes, agravada pela verificação do desastre; associação para delinquir contra o meio ambiente. 
Outro ponto que mereceria maior atenção na legislação penal ambiental diz respeito à possibilidade de ampliar acordos. Afinal, o objetivo maior da Lei dos Crimes Ambientais é o de reparar o dano causado e não o de prender o infrator, pois as consequências socioambientais e econômicas geradas pelo crime de poluição também têm grande impacto em matéria de saúde pública e refletem diretamente nos cofres públicos (SOBRAL, 2019; COSTA, 2019). Evidentemente, este acordo, seja qual for o nome que se lhe dê, seria mais fácil e adequado nas formas de poluição mais simples do que nos grandes acidentes com mortes, estes, sim, a exigir ação penal e imposição de sanções severas.

Os acordos já existem na esfera penal sob a forma de transação, conforme art. 76 da Lei no 9.099, de 1995, conhecida como Lei dos Juizados Especiais. Muitas destas transações têm se revelado de grande utilidade. Todavia, um aspecto fraco desta opção é o fato de que muitos dos acordos resolvem-se com soluções que não dizem respeito ao meio ambiente. Por exemplo, o infrator concorda com proposta de suspensão do Ministério Público, assumindo o ônus de prestar serviços em uma creche. Esta ação, por mais nobre que seja, nada tem a ver com a restauração do dano ambiental.

Nos crimes de poluição, previstos no art. 54 da Lei no 9.605, de 1998, é possível outro tipo de acordo, este já dependendo de ter sido proposta ação penal, consistente na suspensão do processo (art. 89 da Lei no 9.099, de 1995). O Ministério Público oferece uma proposta ao poluidor e ele, se aceitar, terá o processo suspenso por 2 anos, nos quais deverá reparar o dano ambiental causado ou compensá-lo, caso a restauração seja impossível.

Outro aspecto frágil do sistema de acordos previstos na Lei nº 9.099, de 1995, é o da ausência de estatísticas. Realmente, ninguém sabe como e quantas são as transações feitas nos milhares de Juizados Especiais Criminais do Brasil, nem as suspensões dos processos nas Varas Criminas. A inexistência de indicadores impede que se apure o grau dissuasório da processualística adotada em matéria penal ambiental.

No entanto, muitas destas deficiências são passíveis de correção, bastando a vontade firme dos presidentes dos Tribunais Regionais e de Justiça e do Conselho Nacional de Justiça. Importante também seria a criação de cargos de estatísticos e, consequentemente, o aprimoramento dos dados de forma mais segura.

Registre-se, ainda, a tentativa feita através do Projeto de Lei ํㅡ 882, de 2019 , conhecido como Pacote Anticrime, de estender os acordos a todos os crimes previstos no Código Penal e leis especiais, exceto aqueles considerados hediondos. O Projeto 
criava o art. 28-A, permitindo acordo de não persecução para crimes com pena máxima de 4 anos de reclusão e instituía o artigo 395-A, que permitia acordo em ações penais propostas, conhecido por plea bargain, independentemente da pena imposta.

Ocorre que referido Projeto de Lei foi convertido na Lei no 13.964 , de 2019, na qual 0 art. 395-A foi rejeitado e o art. 28-A foi aprovado apenas para crimes com pena mínima inferior a 4 anos. Com isso o avanço, pelo menos nos processos de crimes ambientais, foi mínimo. Os únicos crimes que poderão, agora, ser objeto de acordo de não persecução penal, são os previstos nos arts. 33, 34, 62, 63, 66, 67, 68, 69 e 69-A, § 1ำ da Lei dos Crimes Ambientais, relacionados com condutas de pesca irregular, contra o Ordenamento Urbano e o Patrimônio Cultural e a Administração Ambiental, todos com a pena máxima estabelecida em 3 anos de detenção ou multa, ou ambas cumulativamente. Finalmente, registre-se que nas ações penais propostas contra pessoas jurídicas a prescrição vem sendo sistematicamente reconhecida pelos tribunais. Isto porque, não havendo pena corporal, a jurisprudência vem entendendo que a prescrição deve ser calculada sobre a pena de multa, o que significa o reduzido prazo de 2 anos, na forma do art. 114 do Código Penal (BRASIL, 2019). Como é fato notório, raros são os processos no Brasil que terminam em prazo inferior a um biênio. Ainda mais em crimes de poluição, onde a prova é sempre complexa e sujeita a longas discussões, inclusive através de prova pericial. Disso resulta grande impunidade em relação às empresas poluidoras e consequente descrédito na efetividade da Justiça.

\section{Conclusão}

As constituições ao redor do mundo, depois da grande Conferência da ONU em Estocolmo, 1992, passaram a dar especial atenção à questão ambiental. Disso decorrem inegáveis benefícios como, por exemplo, o estabelecimento de um dever genérico de não degradar.

A Constituição do Brasil, de 1988, no art. 225, foi extremamente incisiva ao estabelecer que o meio ambiente é direito e dever de todos, sendo responsável, quem the cause dano, administrativa, civil e criminalmente. Já a Constituição da Itália é mais concisa e previu no art. 117 ser da responsabilidade do Estado e de suas regiões, de forma concorrente, legislar sobre a matéria.

A poluição do solo por descarte irregular de resíduos, que é típico problema ambiental com implicações globais e duradoras, não foi objeto de menção explícita em nenhuma das duas constituições, cabendo à legislação ordinária tratar do assunto. 
Assim, não será demais lembrar que, muito embora o gerenciamento adequado de resíduos seja essencial para a construção de cidades sustentáveis, habitáveis e resilientes, sua concretização continua sendo um desafio.

Essa dificuldade não é apenas brasileira, mas também italiana. Embora a evolução da legislação penal ambiental na Itália tenha focado mais a questão dos resíduos do que no Brasil, observam-se três dificuldades comuns a serem superadas em ambos os países: incongruências e insuficiências normativas, problemas de ordem fiscalizatória e a antiga questão relacionada ao limite do exercício dos Poderes de Estado.

A falta de coordenação das disposições recém-introduzidas com o aparato regulador pré-existente é a receita ideal para dificultar a eficácia de uma norma, pois abre oportunidade de argumentações diversas em diferentes instâncias, com a interposição de recursos que prolongam, por anos, a definição do conflito. Neste ponto, Brasil e Itália encontram-se em igualdade de posição.

Entretanto, talvez o ponto de maior gravidade observado no processo de luta italiano contra os crimes de poluição por resíduos é aquele que contrapõe o exercício dos Poderes Executivo e Judiciário.

No caso italiano, destaca-se o embate entre medidas judicias visando estancar o gerenciamento irracional e ilegal de resíduos e a proposição de ações executivas com vistas a afetar a efetividade das medidas judicias. Na verdade, o que existe, no caso, é uma inadmissível e imoral disputa entre a justiça e a política, essa última orientada por interesses econômicos e políticos. Os Poderes de Estado têm, cada um na medida das suas atribuições, também o dever de primar pelo cumprimento da Constituição e zelar pela saúde e segurança dos cidadãos. Qualquer outra postura representa grave e indesculpável desvio de finalidade e incursão indevida na competência alheia, pois pode comprometer o bem da coletividade. As experiências comparadas também servem para orientar o que não deve ser feito. Afinal, conflitos socioambientais se assemelham, mesmo ocorrendo em lugares distintos do mundo.

Para além das questões apontadas, no caso brasileiro, além do aprimoramento normativo criminal ambiental no que concerne às imputações de crime de poluição por resíduos sólidos, há que se investir na estruturação dos órgãos ambientais e capacitação de agentes para o fim de aprimorar a fase probatória dos processos. Em complemento, qualquer alteração normativa não pode ser feita aos retalhos, mas deve ser realizada de forma sistêmica e conectada.

Especificamente em termos normativos, a Lei brasileira da Política Nacional de Resíduos Sólidos disponibilizou ao País os instrumentos para a gestão de material 
descartável, no mesmo patamar que os países desenvolvidos. 0 desafio, contudo, continua sendo sua implementação. Aos governos federal e estaduais, a lei atribuiu a obrigação de estabelecer os planos de resíduos, de garantir a infraestrutura para sua disposição adequada e de fiscalizar a lei. A gestão integrada dos resíduos sólidos, incluída a implantação da coleta seletiva, é de responsabilidade dos governos municipais. Para o setor privado, atribuiu-se a obrigação da logística reversa, ou seja, recuperação dos resíduos produzidos pelo setor e sua destinação adequada. E à população, o papel de acondicionar de forma diferenciada seus resíduos e rejeitos, descartando-os corretamente.

Sintetizando tudo o que foi afirmado, é possível concluir que Itália e Brasil necessitam de maior atenção ao descarte de resíduos sólidos e a punição penal é uma boa forma de alcançar-se tal objetivo. Muito embora a Itália disponha de legislação mais precisa, as ocorrências naquele país são mais graves do que as existentes no Brasil. Mas ambos precisam de leis mais claras e abrangentes e eficiência dos seus sistemas de Justiça.

Em suma, o delineamento de responsabilidades para o cumprimento da legislação pode ser aprimorado. Os aprendizados, erros e acertos da Itália são uma boa lente de observação para fins de evolução, que deve ser orientada pelo bom senso e princípio do estado democrático de direito, tendo-se em mente que, especialmente em matéria criminal, a diferença entre o remédio e o veneno é a dose.

\section{Referências}

ABRELPE. Panorama dos resíduos sólidos no Brasil - 2018/2019. Disponível em: http://abrelpe.org.br/. Acesso em: 1ํ mar. 2019.

AMARELLI, Giuseppe. I nuovi reati ambientali e la responsabilità degli enti collettivi: una grande aspettativa parzialmente delusa. In: Cassazione Penale, fascículo 1, p. 405-424. Milão: Giuffré, 2016.

AMARELLI, Giuseppe. La riforma dei reati ambientali: luci ed ombre di un intervento a lungo atteso. In: Diritto Penale Contemporaneo. Disponível em: https://archiviodpc. dirittopenaleuomo.org/upload/1437826548AMARELLI_2015a.pdf. Acesso em: 1으. mar. 2020.

BANCO MUNDIAL. Solid Waste Management Report. Disponível em: https://www. worldbank.org/en/topic/urbandevelopment/brief/solid-waste-management. Acesso em: 1ㅇdez. 2019. 
BERNASCONI, Costanza. L'ampio spettro di modifiche introdotte dalla l. 68 del 2015 (Disposizioni in materia di delitti contro l'ambiente): i riflessi su eterogenei profili di disciplina. In: La Legislazione Penale, 2016. Departamento de Direito, Università degli Studi di Torino.

BERNASCONI, Costanza. Il reato ambientale. Tipicità, offensività, antigiuridicità, colpevolezza. Pisa: Edizioni ETS, 2008.

BERTUZZI, Rosa. La nuova definizione di “Ambiente” secondo la Corte Costituzionale, nota a C. Cost., 23 gennaio 2009, n. 12. Disponível em: www.federalismi.it. Acesso em: 6 set. 2020 .

BONGIORNO, Chiara. La lotta alle ecomafie tra tutela dell'ambiente e ordine pubblico: un equilibrio precario attraverso l'(ab)uso di concetti elastici. In: Diritto Penale Contemporaneo. Milão. 2012.

BRASIL. [Constituição (1988)]. Constituição da República Federativa do Brasil de 1988. Brasília, DF: Presidência da República, [2020]. Disponível em: http://www. planalto.gov.br/ccivil_03/constituicao/constituicao.htm. Acesso em: 26 fev. 2020.

BRASIL. Lei no 6.936, de 31 de agosto de 1981. Dispõe sobre a Política Nacional do Meio Ambiente, seus fins e mecanismos de formulação e aplicação, e dá outras providências. Disponível em: http://www.planalto.gov.br/ccivil_03/LEIS/L6938.htm. Acesso em: 26 fev. 2020.

BRASIL. Lei no 9.605, de 12 de fevereiro de 1988. Dispõe sobre as sanções penais e administrativas derivadas de condutas e atividades lesivas ao meio ambiente, e dá outras providências. Disponível em: http://www.planalto.gov.br/ccivil_03/leis/ 19605.htm. Acesso em: 26 fev. 2020.

BRASIL. Lei no 12.305, de 2 de agosto de 2010. Institui a Política Nacional de Resíduos Sólidos; altera a Lei no 9.605, de 12 de fevereiro de 1998; e dá outras providências. Disponível em: http://www.planalto.gov.br/ccivil_03/_ato2007-2010/2010/lei/L12305. htm. Acesso em: 26 fev. 2020.

BRASIL. Resolução Conama 450, de 6 de março de 2012. Disponível em: http:// www2.mma.gov.br/port/conama/legiabre.cfm?codlegi=674. Acesso em: 26 fev. 2020.

BRASIL. Tribunal de Justiça de Santa Catarina. Apelação Criminal 000713793.2013.8.24.0079. Relator Desembargador José Everaldo Silva; 4ạ. Câmara Criminal, Videira; DJe 14 nov. 2019.

BRASIL. Tribunal de Justiça do Rio Grande do Sul. Ação Penal 70043993880. Desembargador Gaspar Marques Batista; 4a. Câmara Criminal; Porto Alegre, Dje: 27 out. 2011. 
CATENACCI, Mauro. La tutela penale dell'ambiente: contributo all'analisi delle norme penali a struttura "sanzionatoria". Padova: CEDAM, 1996.

CONSULICH, F. Il giudice e il mosaico. La tutela dell'ambiente, tra diritto dell'Unione e pena nazionale. La legislazione Penale, n. 7, 2018. Departamento de Direito, Università degli Studi di Torino.

COTTU, Enrico. La prescrizione dei reati ambientali: efficacia, coerenza, ragionevolezza? Diritto Penale Contemporaneo, n. 1, 2018.

DE SANTIS, Giovanni. La tutela penale dell'ambiente dopo il D. Lgs. n. 121/2011 di attuazione della direttiva 2008/99/CE. Responsabilità Civile e Previdenza, fasc. 2. Milão: Giuffrè, 2012.

DE SANTIS, Giovanni. Diritto penale dell'ambiente: un'ipotesi sistematica. Milão: Giuffrè, 2012.

FIORELLA, Antonio; CATENACCI, M. et al. Questioni fondamentali della parte speciale del diritto penale. Turim: G Giappichelli Editore, 2016.

FORZATI, Francesco. Irrilevanza penale del disastro ambientale, regime derogatorio dei diritti e legislazione emergenziale: i casi Eternit, Ilva ed Emergenza Rifiuti in Campania. Lo stato d'eccezione oltre lo Stato di diritto. Diritto Penale Contemporaneo, 2015. Disponível em: https://archiviodpc.dirittopenaleuomo.org/ upload/1426012622FORZATI_2015a.pdf. Acesso em: 23 mar. 2020.

FREITAS, Vladimir Passos de; FREITAS, Gilberto Passos de. Crimes contra a natureza. 9. ed. São Paulo: Revista dos Tribunais, 2012.

GATTA, Gian Luigi. Il diritto e la giustizia penale davanti al dramma dell'amianto: riflettendo sull'epilogo del caso Eternit. In: Diritto Penale Contemporaneo, 2015. Disponível em: https://archiviodpc.dirittopenaleuomo.org/foto/3260DPC_ Trim_1_2015.pdf\#page=83 \&view=Fit. Acesso em: 24 mar. 2020.

ITÁLIA. Decreto no 1398, de 19 de outubro de 1939. Código Penal. Disponível em: https://www.altalex.com/documents/news/2020/07/07/decreto-semplificazioni. Acesso em: 6 set. 2020.

ITÁLIA. Lei no 68, de 22 de maio de 2015. Disposições relativas a crimes contra o meio ambiente. Disponível em: http://www.lalegislazionepenale.eu/wp-content/ uploads/2016/01/studi_art68_1-co1_Patrono.pdf. Acesso em: 6 set. 2020.

ITÁLIA. Lei no 231, de 3 de dezembro de 2012. Dispõe sobre medida urgente de protecção do meio ambiente, do meio ambiente e dos meios de subsistência do emprego, em caso de crise de estabilização industrial de interesse estratégico nacional. Disponível em: https://www.normattiva.it/uri-res/N2Ls?urn:nir:stato:leg ge:2012;231. Acesso em 6. set. 2020. 
ITÁLIA. Tribunal de Nápole. Sentença. Réus: Francesco Bidognetti; Domenico Pinto; Giuseppe Valente. Autor: Ministério Público. Disponível em: https://www.csm.it/ documents/21768/258667/Tribunale+Napoli+13+novembre+2013/1936ecdc-725c8cf3-0cfd-bb349f1662aa. Acesso em: 6 set. 2020.

ITÁLIA. Lei no 210, de 30 de dezembro de 2008. Conversão em lei, com alterações, do decreto-lei 6 de novembro de 2008, n. 172, que contém medidas extraordinárias para fazer face à emergência no sector da eliminação de resíduos na região da Campânia, bem como medidas urgentes de protecção ambiental. Disponível em: https://www.altalex.com/documents/leggi/2009/01/07/legge-30-12-2008-n-210. Acesso em: 6 set. 2020.

ITÁLIA. Lei no 58, de 28 de junho de 2019. Conversão decreto n. 34, de 30 de abril de 2019. Disponível em: https://www.gazzettaufficiale.it/eli/id/2019/06/29/19G00066/ sg. Acesso em: 7 set. 2020.

ITÁLIA. Lei no 128, de 2 de novembro de 2019. Conversão decreto n. 101, de 3 de setembro de 2019. Disponível em: https://www.gazzettaufficiale.it/eli/ id/2019/11/02/19G00137/sg. Acesso em: 7 set. 2020.

ITÁLIA. Corte de Apelação. Acórdão no 2659, de 21 gennaio 2014. Disponível em: https://renatodisa.com/corte-di-cassazione-sezione-vi-sentenza-21-gennaio-2014n-2659-annullato-il-provvedimento-di-sequestro-in-danno-del-ilva-per-81-mld-dieuro-per-essere-viziato-da-abnormita/. Acesso em: 7 set. 2020.

ITÁLIA. Corte de Apelação. Acórdão n 45935, de 12 de novembro de 2019. Disponível em: http://www.cortedicassazione.it/corte-di-cassazione/. Acesso em: 7 set. 2020.

LO MONTE, Elio. Ecomafia: il controllo penale tra simbolicità ed effettività. In: AA. V., Nuove strategie per la lotta al crimine organizzato trasnazionale, Turim: Giappichelli, 2003.

LUHMANN, Niklas. Risk: a sociological theory. Abingdon (Reino Unido): Routledge, 2017.

PINEDA, Jesús Alfonso Soto (ed.). Planned obsolescence and the rule of law. Universidad Externado de Colombia, 2019.

PLANTAMURA, Vito. Ecomafia, reati associativi e diritto penale dell'economia. Rivista trimestrale di diritto penale dell'economia. Padova: CEDAM, 2007.

PULITANÒ, Domenico. Fra giustizia penale e gestione amministrativa: riflessioni a margine del caso Ilva. In: Diritto Penale Contemporaneo, v. 1, 2013. Disponível em: http://dpc-rivista-trimestrale.criminaljusticenetwork.eu/pdf/DPC_Trim_1_201350-60.pdf. Acesso em: 24 mar. 2020. 
RAMACCI, L. Prime osservazioni sull'introduzione dei delitti contro l'ambiente nel codice penale e le altre disposizioni della legge 22 maggio 2015 n.68. Lexambiente, $n$. 68,v. 8, 2015.Disponível em:http://lexambiente.it/materie/ambiente-in-genere/188dottrina188/11562-ambiente-in-genere-prime-osservazioni-sull-introduzione-deidelitti-contro-l-ambiente-nel-codice-penale-e-le-altre-disposizioni-della-legge22-maggio-2015-n-68.html. Acesso em: 23 mar. 2020.

RAMACCI, L. I reati ambientali ed il principio di offensività. In: Giurisprudenza di merito, v. 4, 2003. Disponível em: http://luca.ramacci.free.fr/varie/offensiv.pdf. Acesso em: 23 mar. 2020.

RIVA, Carlo Ruga. Diritto penale dell'ambiente: parte generale: principi, beni e tecniche di tutela; Parte speciale: Reati contenuti nel d. lgs. n. 152/2006 e nel codice penale. Turim: G Giappichelli Editore, 2016.

RIVA, Carlo Ruga. I nuovi ecoreati: Commento alla legge 22 maggio. 2015, n. 68. Turim: G Giappichelli Editore, 2015.

ROMANO, Bartolomeo (cur.), I reati ambientali alla luce del diritto dell'Unione europea. Padova: CEDAM, 2013.

SÁNCHEZ, Bernardo J. Feijóo. Cuestiones basicas sobre la responsabilidad penal de las personas jurídicas, de outras personas morales y de agrupaciones y asociaciones de personas. Revista Brasileira de Ciências Criminais, ano 7, 27, p. 20-48. jul./set. 1999.

SIRACUSA, Licia. La tutela penale dell'ambiente: bene giuridico e tecniche di incriminazione. Milão: Giuffrè Editore, v. 58, 2007.

SOBRAL, Marcos Felipe Falcão; SOBRAL, Ana Iza Gomes da Penha. Casos de dengue e coleta de lixo urbano: um estudo na Cidade do Recife. Brasil. Ciência \& Saúde Coletiva, v. 24, p. 1075-1082, 2019.

VERGINE, A. L. Il cd .disastro ambientale: l'involuzione interpretativa dell'art. 434 cod. pen. (parte seconda). Ambiente \& Sviluppo, n. 6, 2013. 